\title{
Childhood maltreatment severity is associated with elevated C-reactive protein and body mass index in adult with schizophrenia and bipolar diagnoses
}

Monica Aas ${ }^{1 *}$, Ingrid Dieset ${ }^{1}$, Sigrun Hope ${ }^{1}$, Eva Hoseth ${ }^{1}$, Ragni Mørch ${ }^{1}$, Elina Reponen ${ }^{1}$, Nils Eiel Steen ${ }^{1-2}$, Jannicke F. Anderssen ${ }^{1}$, Thor Ueland ${ }^{3-5}$, Pål Aukrust ${ }^{3-5}$, Ingrid Agartz ${ }^{1,6,7}$,

Ole A. Andreassen ${ }^{1}$, Ingrid Melle ${ }^{1}$

${ }^{1}$ NORMENT K.G Jebsen Centre for Psychosis Research, Institute of Clinical Medicine, Norway;

${ }^{2}$ Drammen District Psychiatric Center, Clinic of Mental Health and Addiction, Vestre Viken Hospital Trust, Drammen, Norway;

${ }^{3}$ Research Institute of Internal Medicine, Oslo University Hospital Rikshospitalet, Oslo, Norway;

${ }^{4}$ Section of Clinical Immunology and Infectious Diseases, Oslo University Hospital, Rikshospitalet, Norway;

${ }^{5}$ K.G. Jebsen Inflammatory Research Center, University of Oslo, Oslo, Norway;

${ }^{6}$ Department of Psychiatric Research, Diakonhjemmet Hospital, Oslo, Norway, and

${ }^{7}$ Department of Clinical Neuroscience, Karolinska Institutet, Stockholm, Sweden

*Corresponding Author:

Monica Aas, $\mathrm{PhD}$

NORMENT KG Jebsen Psychosis Research Centre

Division of Mental Health and Addiction, Institute of Clinical Medicine

Bygg 49, Ullevål sykehus,

PO Box 4956 Nydalen, 0424 Oslo, Norway

Email: monica.aas@medisin.uio.no

Keywords: Childhood trauma; inflammation; BMI, schizophrenia, bipolar disorders. 


\begin{abstract}
BACKGROUND: Several studies have described an association between childhood maltreatment and inflammatory markers in the psychotic disorders (schizophrenia [SZ] and bipolar disorder $[\mathrm{BD}])$. Previous studies have been relatively small ( $<50$ participants), and the severity of abuse and the putative influence of body mass index (BMI) have not been properly investigated.

METHODS: The combined effects of childhood abuse severity and clinical diagnosis on inflammatory markers were investigated in a large sample $(n=483)$ of patients with a disorder on the psychosis spectrum and in healthy controls (HCs). Plasma levels of inflammatory markers (high-sensitivity C-reactive protein [hs-CRP], soluble tumor necrosis factor receptor type 1 [TNFR-R1], glycoprotein 130 [gp130]) were analyzed, and BMI and data on childhood trauma events, on the basis of the Childhood Trauma Questionnaire (CTQ), were obtained from all participants.
\end{abstract}

RESULTS: Patients had increased levels of hs-CRP $(P<0.001$, Cohens $d=0.4)$, lower levels of gp130 $(P<0.001$, Cohens $d=0.5)$, higher BMI $(P<0.001$, Cohens $d=0.5)$ and reported more childhood maltreatment experiences $(P<0.001$, Cohens $d=1.2)$ than the HC group. The severity of childhood abuse (up to three types of abuse: sexual abuse, physical abuse, and emotional abuse) was associated with elevated BMI ( $\mathrm{f}=8.46, P<0.001$, Cohen's $d=0.5)$ and hs-CRP ( $\mathrm{f}=5.47, P=0.001$, Cohen's $d=0.3$ ). Combined effects of patient status and severity of childhood abuse were found for elevated hs-CRP ( $f=4.76, P<0.001$, Cohen's $d=0.4)$. Differences among the groups disappeared when BMI was added to the model.

\title{
DISCUSSION:
}

Trauma-altered immune activation via elevated hs-CRP in patients with SZ and BD may be mediated by higher BMI; however, the direction of this association needs further clarification. 


\section{INTRODUCTION}

The immune system has been suggested to play a role in the pathophysiology of schizophrenia (SZ) and bipolar disorder (BD) (Leboyer et al., 2016, Morch et al., 2016), and we and others have shown that patients with SZ or BD show signs of an activated immune system, including increased levels of C-reactive protein (CRP) as well as more specific markers of the tumor necrosis factor (TNF), interleukin (IL)-1 and the IL-6 system (Dieset et al., 2012b, Hope et al., 2009).

Recent genome-wide association studies (GWAS) have indicated immune genes as susceptibility genes in individuals with SZ, including the major histocompatibility complex (MHC) (2014, Ripke et al., 2011, Stefansson et al., 2009). Regions and genes within the MHC region and the HLA locus, and upregulation of the NOTCH4 gene, have been implicated in individuals with SZ and BD (Dieset et al., 2012a, Leboyer et al., 2016). Both SZ and BD are highly heritable polygenetic diseases on the opposite ends of the psychosis continuum spectrum (Craddock et al., 2009, Craddock and Owen, 2010). Beyond genes in the MHC region, genes encoding innate immune system proteins, such as the toll-like receptors TLR-4 and TLR-2, have been suggested to be central markers of immune defense against diseases (Leboyer et al., 2016).

The brain and the immune system are not fully developed at birth, and early experiences can shape the relationship between the immune system and the brain (Danese and S, 2016). In addition to genetic markers, environmental factors that affect the immune system have been associated with the development of $\mathrm{SZ}$ and $\mathrm{BD}$, including obstetric complications, infection during pregnancy (Brown, 2011, 2015), and childhood maltreatment (Danese et al., 2008, Danese et al., 2007, Elenkov et al., 1999). Recent meta-analyses have suggested that childhood maltreatment may trigger low-grade immune activation, as reflected by increased 
circulating levels of CRP, TNF and IL-6 (Baumeister et al., 2015, Coelho et al., 2014). Several studies using limited sample sizes $(\mathrm{n}<50)$ have investigated childhood maltreatment and inflammation in individuals with SZ, and have found higher levels of IL-6, TNF and CRP in people with childhood maltreatment (Dennison et al., 2012, Hepgul et al., 2012), thus mirroring the observations in adult individuals with SZ and BD (Dieset et al., 2012b, Hope et al., 2009).

Childhood maltreatment is more frequent in patients with severe mental illness, including SZ and BD (Aas et al., 2016, Etain et al., 2008, Larsson et al., 2013), and may contribute to disease development and disease severity at least partly through immune activation. A genetic overlap between inflammation and stress markers has been reported in patients within the psychosis spectrum (Fillman et al., 2014), thus supporting the presence of a stress-immune vulnerability in this group. Furthermore, prenatal immune stimulation in mice interacts with peripubertal stress exposure and consequently increases the likelihood of developing neuroimmunological changes later in life, thus supporting a synergistic relationship between immune activation and early life stress (Giovanoli et al., 2013).

In addition to early life stress, patients with SZ and BD present with an adverse metabolic profile, including a higher body mass index (BMI) (Coodin, 2001), which may contribute to systemic inflammation through production of inflammatory mediators by adipose tissue (Festa et al., 2001). Interestingly, a history of childhood trauma has also been associated with higher BMI via emotional eating (Danese et al., 2014). Together, these findings indicate that childhood maltreatment may interact with a genetic vulnerability to the disease, thus suggesting a double-hit model in which maltreatment subsequently causes elevated immune activation in individuals with $\mathrm{SZ}$ and BD. 
Study hypotheses: First, we hypothesized that the number of childhood abuse events is associated with elevated inflammatory markers (i.e., the general inflammatory marker highsensitivity [hs]-CRP and markers of activation of the TNF [soluble TNF receptor type 1 [sTNF-R1]] and IL-6 [gp130] system) and higher BMI levels. Second, owing to the suggested role of the immune system in the pathophysiology of SZ and BD (Leboyer et al., 2016, Morch et al., 2016), we hypothesized that patient status and the number of childhood abuse events have combined effects on the level of inflammation, such that patients who have experienced the most childhood abuse should have the most elevated inflammatory markers. Finally, owing to the roles of adipose tissue and BMI on inflammatory markers (Festa et al., 2001), we hypothesized that differences in immune activation between groups are influenced by BMI.

\section{MATERIALS AND METHODS}

\subsection{Participants}

2.2. The participants were recruited consecutively from psychiatric units (outpatient and inpatient) in 4 major hospitals in Oslo, as part of the Thematically Organized Psychosis (TOP) Study. A total of 483 participants (with schizophrenia [n=148] or bipolar disorder $[\mathrm{n}=123])$, and healthy individuals $[\mathrm{n}=212])$ were recruited. Inclusion criteria for the healthy controls were the following: living in the same district as the patients, being between 18 and 65 years and having no lifetime diagnosis of any SCID 1 diagnoses. Exclusion criteria for all groups (patients and controls) included the following: organic psychosis, neurological disorder, intellectual disability (IQ under 70), autoimmune disease or cancer, unstable or uncontrolled medical conditions interfering with brain function, and age outside the range of 18-65 years. The Regional Committee for Medical Research Ethics and the Norwegian Data Inspectorate approved the study. All the participants gave 
written informed consent. The participants were enrolled between 2007 and 2016.

\section{Clinical Assessment}

Trained physicians, psychiatrists and clinical psychologists performed clinical assessments. Diagnoses were based on the Structured Clinical Interview for DSM-IV Axis I disorders (SCID-I), chapters A-E. All clinical personnel completed a training program in diagnostics and symptom rating, which was based on the training program at UCLA (Los Angeles, California). The diagnostic reliability was found to be satisfactory with an overall agreement on DSM-IV diagnostic categories of $82 \%$ and an overall $\kappa$ of 0.77 (95\% CI: 0.60 0.94). The calculated Defined Daily Dosages (DDD) of antipsychotic medication was calculated in accordance with the guidelines from the World Health Organization Collaborating Center for Drug Statistics Methodology (http://www.whocc.no/atcdd).

\subsection{Inflammatory and metabolic markers}

BMI was calculated as the individual's body weight (in kilograms) divided by the square of their height (in meters). Blood sampling was performed between 8 am and 2 pm (in patients) and between 8 am and 5 pm (in healthy controls). The analysis of clinical chemistry parameters was performed at the Department of Clinical Chemistry, Oslo University Hospital, Oslo, Norway, on an Integra 800 from Roche Diagnostics (Basel, Switzerland), by using standard methods.

For the immunological analysis, blood was drawn into EDTA-containing vials, and plasma was extracted and stored at $-80^{\circ} \mathrm{C}$. Plasma levels of hs-CRP, gp130, and sTNF-R1 were measured via enzyme immunoassay (EIA) kits obtained from R\&D systems (Minneapolis MN, USA). Intra-and interassay coefficients of variance were less than $10 \%$. 


\subsection{Childhood Trauma Questionnaire (CTQ)}

To measure childhood adverse events, we used the Childhood Trauma Questionnaire (CTQ), a retrospective questionnaire that assesses traumatic experiences in childhood. The CTQ has answers ranging from "never true", "rarely true", "sometimes true", "often true", to "very true", and it yields a total score as well as five sub-scores: physical, emotional and sexual abuse, physical and emotional neglect (Bernstein et al., 1994). The reliability and validity of the CTQ have been demonstrated previously (Aas et al., 2014b, Bernstein et al., 1994). In this study, the short version (28-item version) of the CTQ was translated into Norwegian. A predefined cut-off score from Bernstein was used to divide into above or below the moderate severe cutoff score as a predefined measure of abuse (Bernstein et al., 1994), see Supplementary Material Table 1.

\subsection{Statistics}

Data were analyzed with Predictive Analytic software, Version 22 (IBM Corp., USA). Continuous variables are presented as median, mean $\pm \mathrm{SD}$. For descriptive analyses (Tables 1 ), we used chi square tests and univariate ANOVAs. For data not normally distributed (BMI, hsCRP, gp130, childhood trauma), Kruskal-Wallis tests, Mann-Whitney U tests, or Spearman's correlation tests were conducted.

Data that were not normally distributed (BMI, hs-CRP, gp130) were log transformed before the parametric analyses. To analyze the level/severity of abuse, trauma data were grouped on the basis of one or more CTQ abuse subtypes with scores above the predefined moderate to severe cutoff score of trauma by Bernstein (Bernstein et al., 1994), divided into abuse groups similar to those described in Etain et al. (2013) and Aas et al. (2014a-b) For an overview of the distribution of the sample, see Supplementary Material Table 2. ANOVAs were performed to investigate group differences in inflammatory markers (hs-CRP, gp130). 
The roles of group status (control/patient) and trauma on levels of inflammatory markers were analyzed. Owing to the high correlation between CTQ neglect items and minimization/denial (MD) score (MacDonald et al., 2015, MacDonald et al., 2016), we focused our main analyses (ANOVAs) on childhood abuse (sexual abuse, physical abuse, and emotional abuse). For the ANOVAs, immune markers were added as the dependent variable (one at a time), and group status (patient/control) and severity of abuse were divided into four groups $(0,1,2,3)$ as independent variables. For the multiple comparisons analyses (see Table 3 and Table 1), Bonferroni adjustment was performed. For Figure 2 and Figure 3, participants were divided into the following groups: "controls with no abuse", n=202, "controls with at least one type of abuse", $n=8$, "patients with no abuse", $n=157$, "patients with one type of abuse", $n=54$, "patients with two types of abuse", n=32, and "patients with three types of abuse", $n=17$. Because only 8 controls had abuse scores above moderate to severe levels and only one control had two types of abuse, abuse in controls was defined as "one or more types of abuse" $(n=8)$. Because BMI may be a moderating factor between childhood maltreatment and inflammatory markers, ANCOVA was conducted with BMI as a covariate. Effect sizes were computed using Cohen's $d$ (Cohen, 1977). Cohen's $d$ was calculated to compare the mean and SD in the high-trauma group to the low-trauma group (Cohen's $d=M_{1}-M_{2} /$ Spooled, where spooled $\left.=\sqrt{ }\left[\left(\mathrm{s}_{1}^{2}+\mathrm{s}_{2}^{2}\right) / 2\right]\right)$. For the ANOVA/ANCOVA analyses, partial eta squared values were transformed into Cohen's $d$ for consistency. Hs-CRP values greater than $20 \mathrm{mg} / \mathrm{L}$ were excluded to avoid those with possible acute inflammation due to infection or injury, and follow-up analyses were restricted to CRP $<10 \mathrm{mg} / \mathrm{L}$.

To rule out that inclusion of the time of blood sampling might have influenced the results, follow-up analyses were conducted by adjusting for the time of the blood samples. The threshold for statistical significance was set at $p<0.05$ with post hoc Bonferroni corrections. 


\section{RESULTS}

\subsection{Sample characteristics}

Sample demographics and clinical characteristics are shown in Table 1. One hundred ninety-one (70.5\%) patients were taking at least one type of antipsychotic medication; eighty (29.5\%) patients used antidepressants. The mean age of the patients was $30.3 \pm 10.6$ years, and $51 \%$ of the patients were males. Patients with SZ were younger than both patients with BD and the control group (Table 1). A significant difference among the three groups was also found for sex distribution ( $P=0.002)$ : the BD group was almost $60 \%$ female, whereas the $\mathrm{SZ}$ and $\mathrm{HC}$ groups were $41 \%$ female. Patients reported more childhood maltreatment events than HC individuals $(P<0.001)$. No differences in abuse illness/severity (sexual, physical or emotional abuse) were observed between $\mathrm{SZ}$ and $\mathrm{BD}\left(\mathrm{X}^{2}=5.11, \mathrm{df}=3, P=0.16\right) . \mathrm{SZ}$ and $\mathrm{BD}$ individuals had higher hs-CRP levels $(\mathrm{p}<0.001)$ and BMI $(\mathrm{p}<0.001)$ as well as lower gp130 $(P<0.001)$ than HCs. In contrast, no significant differences in sTNFR1 were observed between the patients (SZ and BD) and the controls $(\mathrm{p}>0.1)$. No associations were observed between defined daily dose (DDD) and immune markers $(P>1.0)$ or DDD and diagnosis $(P>1.0)$. The severity of childhood abuse (sexual abuse, physical abuse, and emotional abuse), which was divided into no abuse $(n=358)$, one type of abuse $(n=61)$, two types of abuse $(n=33)$, and three types of abuse $(n=17)$, was associated with elevated BMI (ANOVA: $f=8.46$, $P<0.001$, Cohen's $d=0.5$ ) and higher hs-CRP level (ANOVA: $\mathrm{f}=5.47, P=0.001$, Cohen's $d=0.3$ ) (see Figure 1 and Figure 2). Bonferroni corrections for multiple comparisons were performed for post hoc tests.

-Table 1, Figure 1-2 around here- 


\subsection{Investigating the effects of patient status and childhood abuse severity on hs-CRP levels}

A significant difference in hs-CRP was observed among the groups: HCs without childhood abuse had the lowest hs-CRP, and patients with three types of abuse (sexual, physical, and emotional) had the highest hs-CRP (see Figure 3, Table 2). Post hoc tests showed that patients with three types of abuse had higher hs-CRP levels than patients with no childhood abuse (mean $\pm \mathrm{SD}=5.08 \pm 3.81$ vs $3.12 \pm 3.09, P=0.007$, Cohen's $d=0.6$ ). Patients without childhood abuse had higher hs-CRP than HCs without childhood abuse (mean $\pm \mathrm{SD}=3.12 \pm 3.09$ vs $2.33 \pm 2.50, P=0.007$, Cohen's $d=0.3$ ). These results remained the same when the time of blood sampling was added into the model. When BMI was added into the model, there was no longer a significant difference in hs-CRP levels across groups with different levels of severity of abuse $(P>0.1)$.

-Table 2 and Figure 3 around here-

\subsection{Investigating the effects of patient status and childhood abuse severity on gp130 levels}

HCs without abuse had the highest gp130, and patients with three types of abuse had the lowest gp130 (see Figure 4). These results remained the same after the time of blood sampling and BMI were added into the models. No significant difference in gp130 and severity of abuse was observed (see Table S3).

-Figure 4 around here-

To rule out that acute inflammation might have been driving our results, follow-up analyses were conducted only in participants with hs-CRP $<10 \mathrm{mg} / \mathrm{L}$ (23 participants were 
excluded), showing similar results. More trauma experiences were still associated with higher hs-CRP and higher BMI (data available on request). Finally, no associations were observed between sTNFR-1 and childhood abuse $(\mathrm{p}<0.01)$.

\section{DISCUSSION}

Our study is, to our knowledge, the largest study to show an association between childhood abuse and activation of immune markers in patients with SZ or BD (measured as one group) and HCs. Our study demonstrates combined effects of the level/severity of childhood maltreatment and a psychosis spectrum diagnosis on elevated immune activation. Participants who reported severe childhood abuse were also more likely to be obese, contributing to the elevated hs-CRP in the patient group. Our data also demonstrated lower levels of gp130, an antagonist for IL-6, in participants with childhood abuse, thus potentially suggesting increased IL-6 activity in trauma victims. In contrast to the studies by Dennison et al., (2012) and Hepgul et al., (2012), we also found significantly higher levels of immune markers in patients without childhood maltreatment than those found in HCs. Our study was larger than the two previous studies, and the differences between the studies may be related to the higher power in our study.

Our study supports the hypothesis that increased adiposity, as reflected by higher BMI, may mediate the effects of childhood maltreatment on CRP levels. Our finding that participants who had experienced childhood maltreatment were more likely to be obese is consistent with a recent meta-analysis by Danese et al. (2014) comprising 190,285 participants, which has suggested that childhood maltreatment is a risk factor for obesity over the course of life. In addition to emotional eating, elevated inflammation levels in maltreated individuals may induce fatigue and reduced activity (Dantzer et al., 2008, Miller et al., 2009), 
thereby further contributing to obesity and increased inflammation in adulthood and potentially representing a pathogenic loop in these individuals. This possibility is consistent with an association between BMI and inflammatory markers, including CRP, both in childhood (Siervo et al., 2012) and adulthood (Festa et al., 2001). No association between inflammatory markers and medication (measured by DDD) was observed, thus indicating that changes in BMI were not related to medication in our sample. Notably, both obesity and hsCRP are risk factors for the development of type 2 diabetes, cardiovascular disease and functional disability (Noble et al., 2010, Ribeiro-Santos et al., 2014, Van Gaal et al., 2006), and comorbid general medical illnesses have been proposed to contribute to the reduced physical health observed in patients with SZ and BD (Kessing et al., 2015). Hence, childhood maltreatment might have long-lasting effects that contribute to reduced physical health in individuals with $\mathrm{SZ}$ and $\mathrm{BD}$ via alterations in immune-inflammatory markers and obesity. Our study confirms this effect in the largest sample of SZ, BD, and HCs in the literature and includes levels of the severity of abuse in this context.

Our data suggest combined effects of childhood maltreatment (sexual abuse, emotional abuse, and physical abuse) and patient status on elevated hs-CRP levels. It is possible that these patients may be specifically vulnerable to the negative effects of childhood trauma, owing to increased exposure to trauma (Aas et al., 2016, Mondelli et al., 2010) and genetic makeup, which includes immune-related genes as risk genes for SZ and BD (Consortium., 2015, Consortium., 2014). Recent studies have shown that immune cells can cross the bloodbrain barrier and that the blood-brain barrier becomes more "leaky" in these disease states (Banks and Erickson, 2010, Beumer et al., 2012, Dieset et al., 2016, Khandaker and Dantzer, 2016), thus potentially contributing to increased inflammation in the central nervous system. Prenatal and perinatal infections can also disrupt fetal neurodevelopmental processes and lead to long-lasting changes in the brain and an increased risk of psychotic disturbances in early 
adulthood (Meyer et al., 2009). However, owing to the cross-sectional design of our study, we cannot conclude whether the increased presence of immune markers in the patients was related to the development of the illness or was simply a secondary phenomenon resulting from the illness. Our study is the first to show that the number of different types of childhood abuse experiences is related to higher inflammatory markers in a dose-dependent fashion. This finding was made possible by our large sample size ( $N=483$ participants: schizophrenia $[\mathrm{n}=148]$ or bipolar disorder $[\mathrm{n}=123])$ and healthy individuals $[\mathrm{n}=212])$. This effect has not been possible to investigate in the smaller, previously published schizophrenia studies with $\mathrm{N}<50$ (Dennison et al., 2012, Hepgul et al., 2012). This study is also the first to demonstrate among those with bipolar disorder that elevated inflammatory markers are higher in patients with childhood abuse compared with patients without childhood abuse. Previous smaller studies have found that the presence of childhood abuse (without investigating the number of childhood abuse subtypes) is associated with elevated immune markers in the schizophrenia spectrum (Dennison et al., 2012, Hepgul et al., 2012), but no previous studies have included bipolar patients.

Strengths and limitations: The study included a large and well characterized sample size. However, blood samples were collected at different times, and not all of the subjects were fasting; however, the inclusion of the time of blood sampling into the model did not improve the model or change the findings. Furthermore, the data on childhood maltreatment were collected retrospectively, but the retrospective design has been found to be satisfactory in the collection of childhood maltreatment information in patients with severe mental disorders (Fisher et al., 2011). Reports of childhood maltreatment have been found to be stable over time in addition to a large overlap of reports of childhood maltreatment across various sources (e.g., clinical case notes, questionnaires) (Fisher et al., 2011). We cannot rule out that our findings might be specific to schizophrenia or bipolar illness, because similar 
findings are present in other mental disorders, such as in unipolar depression. Causality cannot be inferred, because this was a cross-sectional study and not a prospective long-term study. In this study, we investigated BMI levels as a measure of obesity and several immune markers, both being associated with poor physical heath (Noble et al., 2010, Ribeiro-Santos et al., 2014, Van Gaal et al., 2006). However, it should be noted that physical heath also includes parameters not measured in this study. Furthermore, gp130 receptor levels are not exclusive to IL-6 levels, because several other proteins might be associated with gp-130. It should also be noted that the control group with childhood abuse was small $(n=8)$, and we were not able to investigate the severity of abuse in the control sample. Owing to the small number of controls with abuse, interaction analyses of group (control/patients) $\mathrm{x}$ trauma on inflammatory activation was not performed.

Our study supports a broader traumatic non-specific increase in immune activation via elevated hs-CRP in patients with SZ and BD. Participants who reported more types of childhood abuse were also more likely to be obese, thus potentially contributing to the elevated hs-CRP in the patient group.

Clinical relevance: Patients with an SZ or BD illness who report a history of childhood maltreatment are at risk of obesity and elevated immune system components (hsCRP), both of which are risk factors for reduced physical health. Thus, in these patients, strategies to improve physical health behavior should be addressed in conjunction with regular treatment. 


\section{FIGURE LEGENDS}

Figure 1: Participants with more types of childhood abuse have higher BMI levels.

Figure 2: Participants with more types of childhood abuse have higher hs-CRP.

Figure 3: Combined effects of patient status and childhood abuse severity on elevated hsCRP.

Figure 4: Controls without abuse had the highest gp130. 


\section{References}

Aas, M., Andreassen, O. A., Aminoff, S. R., Faerden, A., Romm, K. L., Nesvag, R., Berg, A. O., Simonsen, C., Agartz, I. \& Melle, I. (2016). A history of childhood trauma is associated with slower improvement rates: Findings from a one-year follow-up study of patients with a firstepisode psychosis. BMC. Psychiatry 16, 126.

Aas, M., Etain, B., Bellivier, F., Henry, C., Lagerberg, T., Ringen, A., Agartz, I., Gard, S., Kahn, J. P., Leboyer, M., Andreassen, O. A. \& Melle, I. (2014a). Additive effects of childhood abuse and cannabis abuse on clinical expressions of bipolar disorders. Psychol Med 44, 1653-62.

Aas, M., Haukvik, U. K., Djurovic, S., Tesli, M., Athanasiu, L., Bjella, T., Hansson, L., Cattaneo, A., Agartz, I., Andreassen, O. A. \& Melle, I. (2014b). Interplay between childhood trauma and BDNF val66met variants on blood BDNF mRNA levels and on hippocampus subfields volumes in schizophrenia spectrum and bipolar disorders. J. Psychiatr. Res. 59, 14-21.

Banks, W. A. \& Erickson, M. A. (2010). The blood-brain barrier and immune function and dysfunction. Neurobiol. Dis 37, 26-32.

Baumeister, D., Akhtar, R., Ciufolini, S., Pariante, C. M. \& Mondelli, V. (2015). Childhood trauma and adulthood inflammation: a meta-analysis of peripheral C-reactive protein, interleukin-6 and tumour necrosis factor-alpha. Mol. Psychiatry. 21, 642-9.

Bernstein, D. P., Fink, L., Handelsman, L., Foote, J., Lovejoy, M., Wenzel, K., Sapareto, E. \& Ruggiero, J. (1994). Initial reliability and validity of a new retrospective measure of child abuse and neglect. Am. J. Psychiatry 151, 1132-1136.

Beumer, W., Gibney, S. M., Drexhage, R. C., Pont-Lezica, L., Doorduin, J., Klein, H. C., Steiner, J., Connor, T. J., Harkin, A., Versnel, M. A. \& Drexhage, H. A. (2012). The immune theory of psychiatric diseases: a key role for activated microglia and circulating monocytes. J. Leukoc. Biol 92, 959-975.

Brown, A. S. (2011). The environment and susceptibility to schizophrenia. Prog Neurobiol 93, 23-58.

Brown, A. S. (2015). The Kraepelinian Dichotomy From the Perspective of Prenatal Infectious and Immunologic Insults. Schizophr Bull 41, 786-91.

Coelho, R., Viola, T. W., Walss-Bass, C., Brietzke, E. \& Grassi-Oliveira, R. (2014). Childhood maltreatment and inflammatory markers: a systematic review. Acta Psychiatr. Scand 129, 180192.

Cohen, J. (1977). Statistical power analysis for the behavioral sciences. New York: Academic Press.

Consortium., N. a. P. A. S. o. t. P. G. (2015). Psychiatric genome-wide association study analyses implicate neuronal, immune and histone pathways. Nat. Neurosci 18, 199-209.

Consortium., S. W. G. o. t. P. G. (2014). Biological insights from 108 schizophrenia-associated genetic loci. Nature 511, 421-427.

Coodin, S. (2001). Body mass index in persons with schizophrenia. Can J Psychiatry 46, 549-55.

Craddock, N., O'Donovan, M. C. \& Owen, M. J. (2009). Psychosis genetics: modeling the relationship between schizophrenia, bipolar disorder, and mixed (or "schizoaffective") psychoses. Schizophr Bull 35, 482-90.

Craddock, N. \& Owen, M. J. (2010). The Kraepelinian dichotomy - going, going... but still not gone. Br J Psychiatry 196, 92-5.

Danese, A., Moffitt, T. E., Pariante, C. M., Ambler, A., Poulton, R. \& Caspi, A. (2008). Elevated inflammation levels in depressed adults with a history of childhood maltreatment. Arch. Gen. Psychiatry 65, 409-415.

Danese, A., Pariante, C. M., Caspi, A., Taylor, A. \& Poulton, R. (2007). Childhood maltreatment predicts adult inflammation in a life-course study. Proc. Natl. Acad. Sci. U. S. A 104, 13191324.

Danese, A., \& Tan, M. (2014). Childhood maltreatment and obesity: systematic review and metaanalysis. Mol. Psychiatry, 19, 544-554.

Danese, A. \& S, J. L. (2017). Psychoneuroimmunology of Early-Life Stress: The Hidden Wounds of Childhood Trauma? Neuropsychopharmacology. 42, 99-114. 
Dantzer, R., O'Connor, J. C., Freund, G. G., Johnson, R. W. \& Kelley, K. W. (2008). From inflammation to sickness and depression: when the immune system subjugates the brain. Nat. Rev. Neurosci 9, 46-56.

Dennison, U., McKernan, D., Cryan, J. \& Dinan, T. (2012). Schizophrenia patients with a history of childhood trauma have a pro-inflammatory phenotype. Psychol Med 42, 1865-71.

Dieset, I., Andreassen, O. A. \& Haukvik, U. K. (2016). Somatic Comorbidity in Schizophrenia: Some Possible Biological Mechanisms Across the Life Span. Schizophr. Bull. 42, 1316-1319.

Dieset, I., Djurovic, S., Tesli, M., Hope, S., Mattingsdal, M., Michelsen, A., Joa, I., Larsen, T. K., Agartz, I., Melle, I., Rossberg, J. I., Aukrust, P., Andreassen, O. A. \& Ueland, T. (2012a). Upregulation of NOTCH4 gene expression in bipolar disorder. Am J Psychiatry 169, 1292-300.

Dieset, I., Hope, S., Ueland, T., Bjella, T., Agartz, I., Melle, I., Aukrust, P., Rossberg, J. I. \& Andreassen, O. A. (2012b). Cardiovascular risk factors during second generation antipsychotic treatment are associated with increased C-reactive protein. Schizophr. Res 140, 169-174.

Elenkov, I. J., Webster, E. L., Torpy, D. J. \& Chrousos, G. P. (1999). Stress, corticotropin-releasing hormone, glucocorticoids, and the immune/inflammatory response: acute and chronic effects. Ann. N. Y. Acad. Sci 876, 1-11.

Etain, B., Henry, C., Bellivier, F., Mathieu, F. \& Leboyer, M. (2008). Beyond genetics: childhood affective trauma in bipolar disorder. Bipolar. Disord 10, 867-876.

Festa, A., D'Agostino, R., Jr., Williams, K., Karter, A. J., Mayer-Davis, E. J., Tracy, R. P. \& Haffner, S. M. (2001). The relation of body fat mass and distribution to markers of chronic inflammation. Int. J. Obes. Relat Metab Disord 25, 1407-1415.

Fillman, S. G., Sinclair, D., Fung, S. J., Webster, M. J. \& Shannon, W. C. (2014). Markers of inflammation and stress distinguish subsets of individuals with schizophrenia and bipolar disorder. Transl. Psychiatry 4, e365.

Fisher, H. L., Craig, T. K., Fearon, P., Morgan, K., Dazzan, P., Lappin, J., Hutchinson, G., Doody, G. A., Jones, P. B., McGuffin, P., Murray, R. M., Leff, J. \& Morgan, C. (2011). Reliability and comparability of psychosis patients' retrospective reports of childhood abuse. Schizophr. Bull 37, 546-553.

Giovanoli, S., Engler, H., Engler, A., Richetto, J., Voget, M., Willi, R., Winter, C., Riva, M. A., Mortensen, P. B., Feldon, J., Schedlowski, M. \& Meyer, U. (2013). Stress in puberty unmasks latent neuropathological consequences of prenatal immune activation in mice. Science 339, 1095-1099.

Hepgul, N., Pariante, C. M., Dipasquale, S., DiForti, M., Taylor, H., Marques, T. R., Morgan, C., Dazzan, P., Murray, R. M. \& Mondelli, V. (2012). Childhood maltreatment is associated with increased body mass index and increased C-reactive protein levels in first-episode psychosis patients. Psychol. Med 42, 1893-1901.

Hope, S., Melle, I., Aukrust, P., Steen, N. E., Birkenaes, A. B., Lorentzen, S., Agartz, I., Ueland, T. \& Andreassen, O. A. (2009). Similar immune profile in bipolar disorder and schizophrenia: selective increase in soluble tumor necrosis factor receptor I and von Willebrand factor. Bipolar. Disord 11, 726-734.

Kessing, L. V., Vradi, E., McIntyre, R. S. \& Andersen, P. K. (2015). Causes of decreased life expectancy over the life span in bipolar disorder. J. Affect. Disord 180, 142-147.

Khandaker, G. M. \& Dantzer, R. (2016). Is there a role for immune-to-brain communication in schizophrenia? Psychopharmacology (Berl) 233, 1559-1573.

Larsson, S., Andreassen, O. A., Aas, M., Rossberg, J. I., Mork, E., Steen, N. E., Barrett, E. A., Lagerberg, T. V., Peleikis, D., Agartz, I., Melle, I. \& Lorentzen, S. (2013). High prevalence of childhood trauma in patients with schizophrenia spectrum and affective disorder. Compr. Psychiatry 54, 123-127.

Leboyer, M., Oliveira, J., Tamouza, R. \& Groc, L. (2016). Is it time for immunopsychiatry in psychotic disorders? Psychopharmacology (Berl) 233, 1651-1660.

MacDonald, K., Thomas, M. L., MacDonald, T. M. \& Sciolla, A. F. (2015). A perfect childhood? Clinical correlates of minimization and denial on the childhood trauma questionnaire. J. Interpers. Violence 30, 988-1009.

MacDonald, K., Thomas, M. L., Sciolla, A. F., Schneider, B., Pappas, K., Bleijenberg, G., Bohus, M., Bekh, B., Carpenter, L., Carr, A., Dannlowski, U., Dorahy, M., Fahlke, C., Finzi-Dottan, R., 
Karu, T., Gerdner, A., Glaesmer, H., Grabe, H. J., Heins, M., Kenny, D. T., Kim, D., Knoop, H., Lobbestael, J., Lochner, C., Lauritzen, G., Ravndal, E., Riggs, S., Sar, V., Schafer, I., Schlosser, N., Schwandt, M. L., Stein, M. B., Subic-Wrana, C., Vogel, M. \& Wingenfeld, K. (2016). Minimization of Childhood Maltreatment Is Common and Consequential: Results from a Large, Multinational Sample Using the Childhood Trauma Questionnaire. PLoS. One 11, e0146058.

Meyer, U., Feldon, J. \& Yee, B. K. (2009). A review of the fetal brain cytokine imbalance hypothesis of schizophrenia. Schizophr. Bull 35, 959-972.

Miller, A. H., Maletic, V. \& Raison, C. L. (2009). Inflammation and its discontents: the role of cytokines in the pathophysiology of major depression. Biol. Psychiatry 65, 732-741.

Mondelli, V., Dazzan, P., Hepgul, N., Di, F. M., Aas, M., D'Albenzio, A., Di, N. M., Fisher, H., Handley, R., Marques, T. R., Morgan, C., Navari, S., Taylor, H., Papadopoulos, A., Aitchison, K. J., Murray, R. M. \& Pariante, C. M. (2010). Abnormal cortisol levels during the day and cortisol awakening response in first-episode psychosis: the role of stress and of antipsychotic treatment. Schizophr. Res 116, 234-242.

Morch, R. H., Dieset, I., Faerden, A., Hope, S., Aas, M., Nerhus, M., Gardsjord, E. S., Joa, I., Morken, G., Agartz, I., Aukrust, P., Djurovic, S., Melle, I., Ueland, T. \& Andreassen, O. A. (2016). Inflammatory evidence for the psychosis continuum model. Psychoneuroendocrinology 67, 189-197.

Noble, J. M., Manly, J. J., Schupf, N., Tang, M. X., Mayeux, R. \& Luchsinger, J. A. (2010). Association of C-reactive protein with cognitive impairment. Arch. Neurol 67, 87-92.

Ribeiro-Santos, A., Lucio, T. A. \& Salgado, J. V. (2014). Evidence for an immune role on cognition in schizophrenia: a systematic review. Curr. Neuropharmacol 12, 273-280.

Ripke, S., Sanders, A. R., Kendler, K. S., Levinson, D. F., Sklar, P., et al., (2009). Common variants conferring risk of schizophrenia. Nature 460, 744-747.

Van Gaal, L. F., Mertens, I. L. \& De Block, C. E. (2006). Mechanisms linking obesity with cardiovascular disease. Nature 444, 875-880. 
Figure 1: Participants with more types of childhood abuse had higher BMI levels

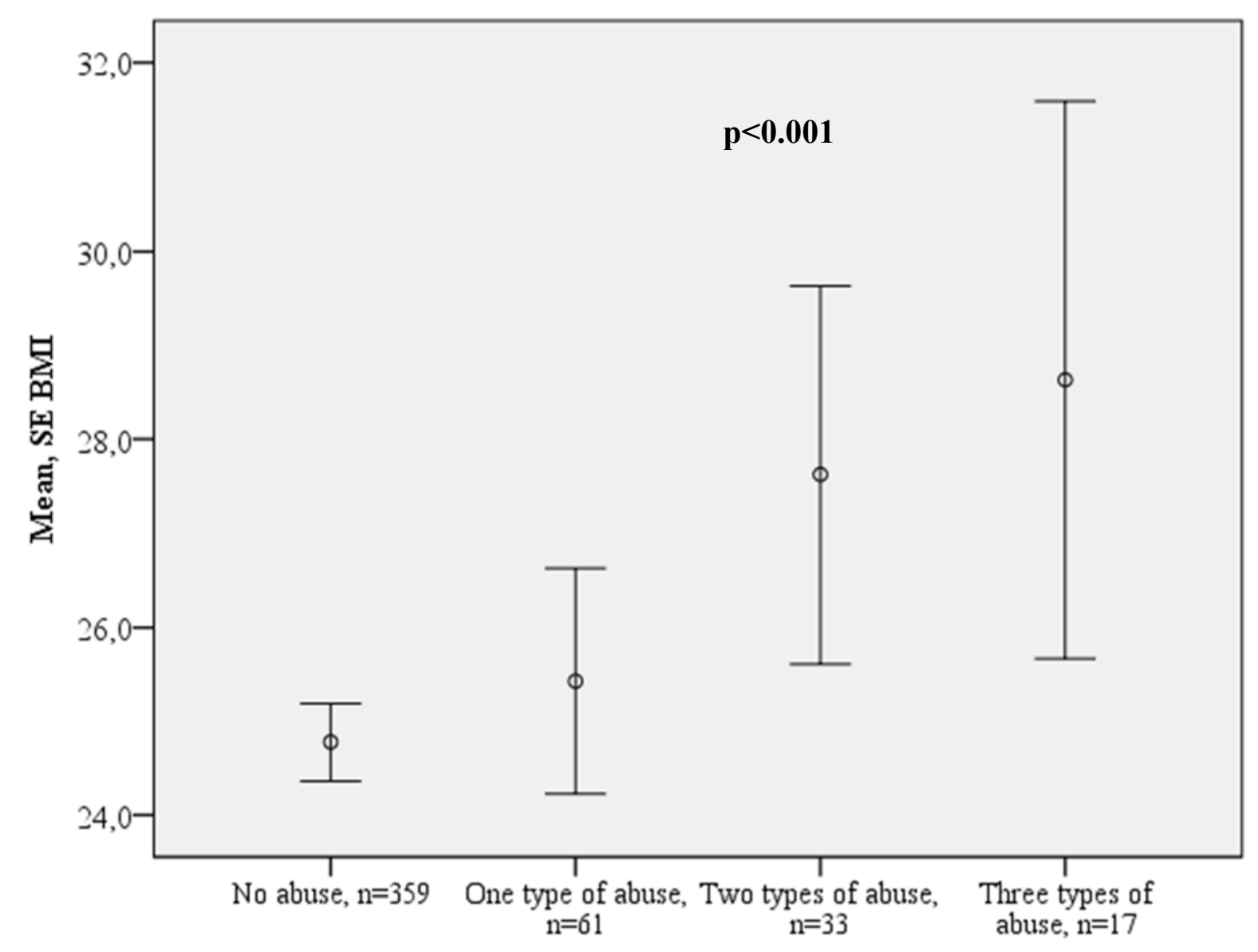

Mean, SE. $\mathrm{f}=8.46, P<0.001$. No abuse, $\mathrm{N}=359$; one type of abuse, $\mathrm{N}=61$; two types of abuse, $\mathrm{N}=33$; three types of abuse subtypes, $\mathrm{N}=17$. 
Figure 2: Participants with higher number of different types of childhood trauma have higher hs-CRP levels

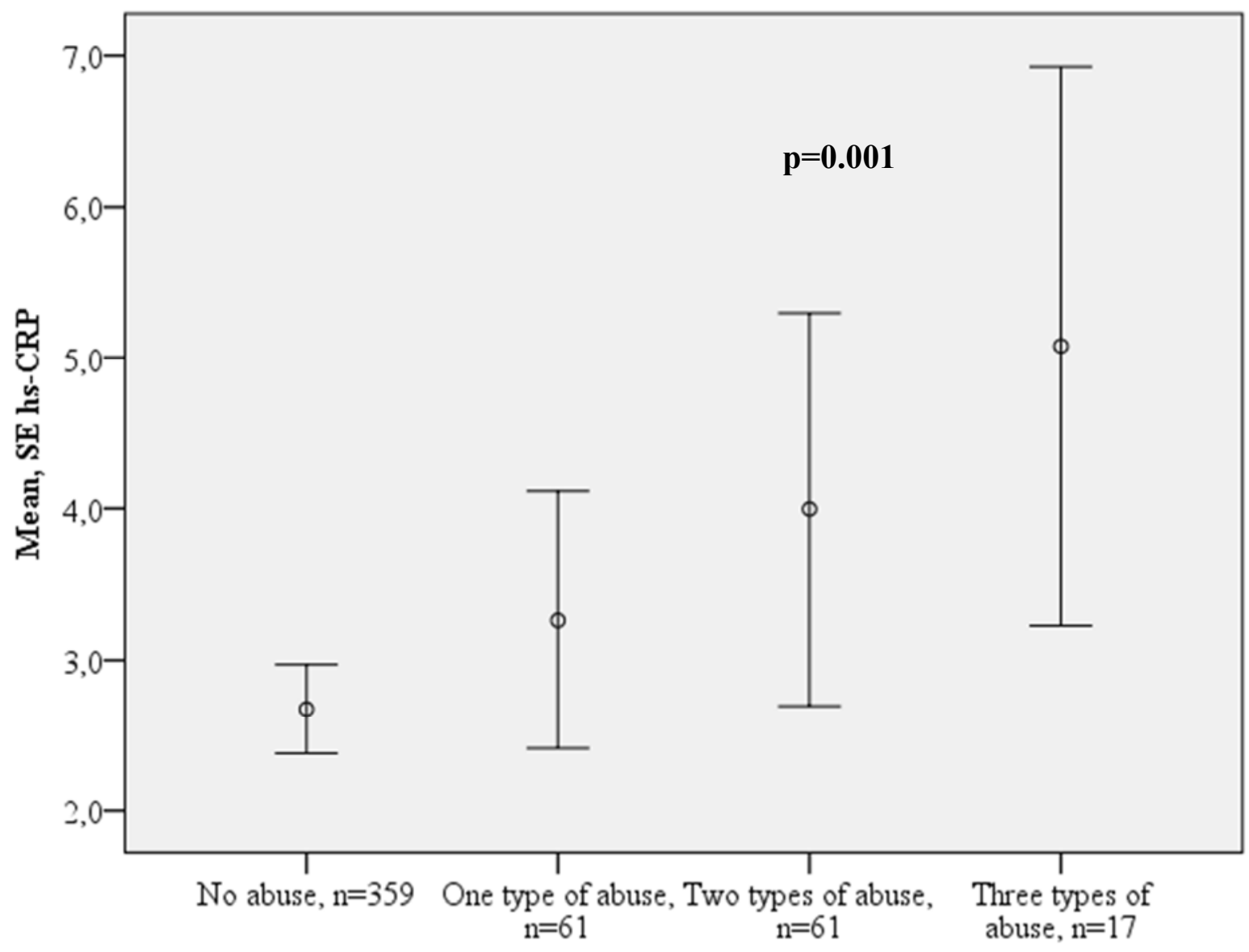

Mean, S.E. $\mathrm{f}=5.47, P<0.001$. No abuse, $\mathrm{N}=359$; one type of abuse, $\mathrm{N}=61$; two types of abuse, $\mathrm{N}=33$; three types of abuse subtypes, $\mathrm{N}=17$. 
Figure 3: Combined effects of patient status and childhood abuse severity on elevated hsCRP

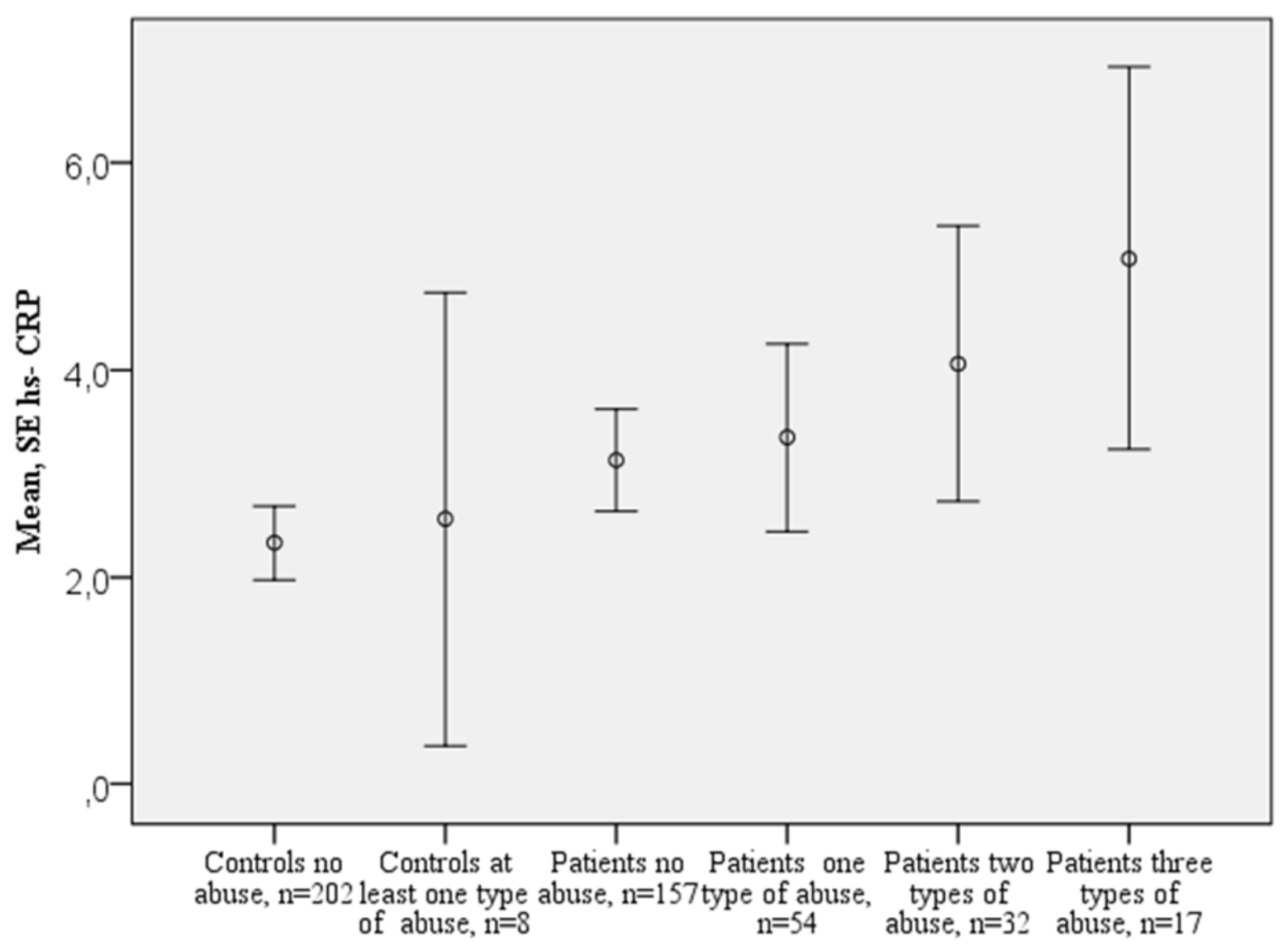

Controls no abuse, $n=202$, controls at least one type of abuse, $n=8$, patients no abuse, $n=157$, patients one type of abuse, $n=54$, patients two types of abuse, $n=32$, patients three types of abuse, $n=17$. 
Figure 4: Controls without abuse had the highest gp130

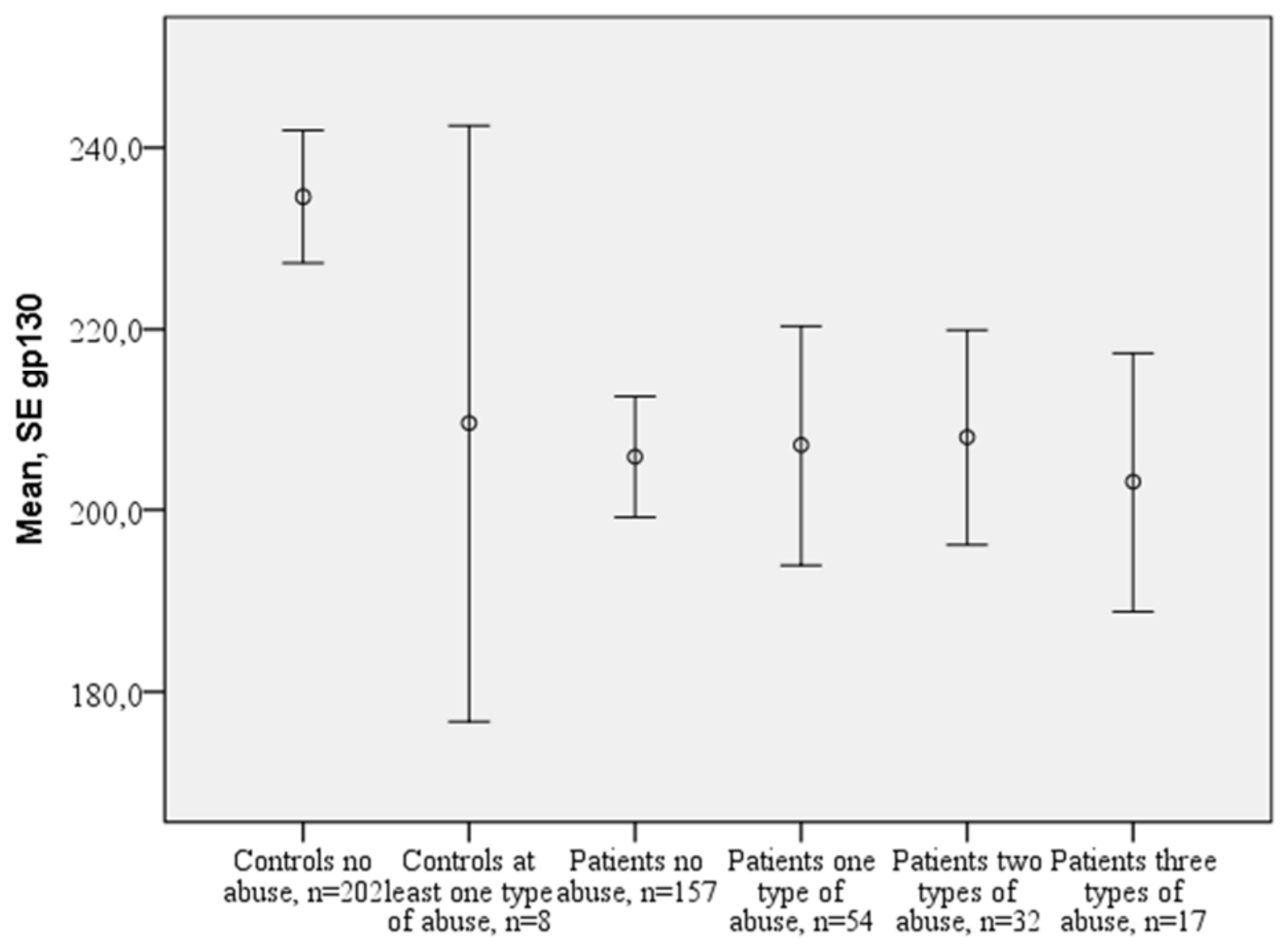

Controls no abuse, $n=202$, controls with at least one type of abuse, $n=8$, patients no abuse, $n=157$, patients with one type of abuse, $n=54$, patients two types of abuse, $n=32$, patients three types of abuse, $n=17$. 
Table 1: Demographics divided into schizophrenia, bipolar disorders and healthy controls

\begin{tabular}{|c|c|c|c|c|c|}
\hline & $\begin{array}{l}\text { Schizophrenia, } \\
\text { SZ (n=148) }\end{array}$ & $\begin{array}{l}\text { Bipolar disorders } \\
\text { BD }(n=123)\end{array}$ & $\begin{array}{l}\text { Healthy individuals } \\
\text { HCs }(\mathrm{n}=212)\end{array}$ & Statistics & $\begin{array}{l}\text { Post-Hoc } \\
\text { Analysis }\end{array}$ \\
\hline $\operatorname{sex}, \mathrm{M}(\%) / \mathrm{F}(\%)^{2}$ & $88(59.0) / 55(41.0)$ & $50(41) / 73(59)$ & $122(59) / 86(41.0)$ & $\begin{array}{l}X^{2}=12.68, \mathrm{df}=2 \\
p=0.002\end{array}$ & $\begin{array}{l}\mathrm{BD}>\mathrm{F} \text { than } \mathrm{SZ} \\
\text { and } \mathrm{HCs}\end{array}$ \\
\hline $\begin{array}{l}\text { Physical abuse, median (min- } \\
\text { max) mean } \pm \mathrm{SD}^{3-4}\end{array}$ & $5(5-25) 7.0 \pm 3.5$ & $5(5-25) 6.5 \pm 3.4$ & $5(5-11) 5.1 \pm 0.6$ & $\begin{array}{l}\mathrm{X}^{2}=84.08, \mathrm{df}=2, \\
\mathrm{p}<0.001\end{array}$ & $\mathrm{HCs}<\mathrm{SZ}$ and $\mathrm{BD}$ \\
\hline $\begin{array}{l}\text { Sexual abuse, Median (min- } \\
\text { max) mean } \pm \mathrm{SD}^{3-4}\end{array}$ & $5(5-21) 6.8 \pm 3.4$ & $5(5-25) 6.8 \pm 3.9$ & $5(5-11) 5.1 \pm 0.6$ & $\begin{array}{l}X^{2}=54.40, d f=2, \\
p<0.001\end{array}$ & $\mathrm{HCs}<\mathrm{SZ}$ and $\mathrm{BD}$ \\
\hline $\begin{array}{l}\text { Hs-CRP, median (min-max) } \\
\text { mean } \pm \mathrm{SD}^{1}\end{array}$ & $2.4(0.2-12.9) 3.4 \pm 3.2$ & $1.7(0.2-13.7) 3.3 \pm 3.4$ & $1.2(0.2-13.5) 2.3 . \pm 2.5$ & $\mathrm{~F}=7.6, \mathrm{df}=2, \mathrm{p}=0.001$ & $\mathrm{HCs}<\mathrm{SZ}$ and $\mathrm{BD}$ \\
\hline $\begin{array}{l}\text { BMI, median (min-max) } \\
\text { mean } \pm \text { SD }^{1}\end{array}$ & $25.9(15.8-45.1) 26.3 \pm 5.5$ & $\begin{array}{l}25.6(18.4-42.5) \\
25.8 \pm 4.3\end{array}$ & $\begin{array}{l}23.5(16.9-38.6) \\
24.0 \pm 3.4\end{array}$ & $\mathrm{~F}=12.3, \mathrm{df}=2, \mathrm{p}<0.001$ & $\mathrm{HCs}<\mathrm{SZ}$ and $\mathrm{BD}$ \\
\hline $\begin{array}{l}\text { sTNFR1, median (min-max) } \\
\text { mean } \pm \mathrm{SD}^{1}\end{array}$ & $1.7(0.17-4.45) 1.8 \pm 0.6$ & $1.6(0.14-4.59) 1.8 \pm 0.7$ & $\begin{array}{l}1.8(0.89- \\
6.23) 1.95 \pm 0.75\end{array}$ & $\mathrm{~F}=2.1, \mathrm{df}=2, \mathrm{p}=0.13$ & N.S \\
\hline $\mathrm{DDD}^{5}$ & $1.0 . \pm 1.3$ & $0.9 \pm 0.7$ & & $t=0.68, \mathrm{p}=0.50$ & N.S \\
\hline
\end{tabular}

1=ANOVA; $2=$ Chi square test; $3=$ Kruskal-Wallis Test; 4=Mann-whitney-U test. $5=$ Defined Daily Dosage (DDD) antipsychotic medication. 
Table 2: Hs-CRP is higher in participants with childhood trauma and in patients compared to controls

\begin{tabular}{|c|c|c|c|c|c|}
\hline Source & df & Mean Square & $\mathrm{F}$ & Sig. & Cohens $d$ \\
\hline Corrected Model & 4 & 51.87 & 5.91 & $<0.001$ & 0.5 \\
\hline Intercept & 1 & 1552.75 & 176.80 & $<0.001$ & 0.3 \\
\hline Severity of abuse & 3 & 24.32 & 2.77 & 0.041 & 0.2 \\
\hline Group(patient/control) & 1 & 61.61 & 7.02 & 0.008 & 0.2 \\
\hline
\end{tabular}

ANOVA, Dependent variable: hs-CRP; Independent variables: group status (patients/controls) and severity of abuse. 


\section{Supplementary Material}

Table S1: CTQ moderate to severe cutoff score for abuse

CTQ, Childhood abuse $\quad$ Moderate to severe cutoff

subtypes

Physical abuse $\quad \geq 10$

Sexual abuse $\quad \geq 8$

Emotional abuse $\quad \geq 13$

For estimates of frequencies of childhood abuse we used the moderate to severe predefined cutoff suggested by Bernstein (Bernstein and Fink, 1998).

Table S2: Number of CTQ abuse subtypes

\begin{tabular}{ll}
\hline CTQ subtypes & 359 \\
Zero & 61 \\
One & 33 \\
Two & 17 \\
Three & \\
\hline "Zero"=no childhood abuse, $\mathrm{n}=359 ;$ "one"=one type of childhood abuse subtype, $\mathrm{n}=61 ;$ \\
"two"=two types of childhood abuse subtypes, $\mathrm{n}=33$; and "three"=three types of childhood \\
abuse subtypes, $\mathrm{n}=17$
\end{tabular}

Table S3: Gp130 is significantly different in patients compared to controls

\begin{tabular}{|l|r|r|r|r|} 
Source & df & Mean Square & \multicolumn{1}{c|}{ F } & \multicolumn{1}{c|}{ Sig. } \\
\hline Corrected Model & 4 & 22049.68 & 10.22 & $<0.001$ \\
\hline Intercept & 1 & 6094155.20 & 2825.02 & $<0.001$ \\
\hline Severity of abuse & 3 & 238.22 & 0.11 & 0.95 \\
\hline Group (patient/control) & 1 & 68414.78 & 31.72 & $<0.001$ \\
\hline
\end{tabular}

